\title{
El interaprendizaje como clave de la educomunicación*
}

\section{Síntesis}

En este artículo, se propone un análisis al papel de las educadoras y educadores universitarios y a la comunicación vigente

en esos espacios sociales. A partir de

una amplia variedad de acechanzas

del intreraprendizaje, el autor genera reflexiones en torno a la edocomunicación, la construcción de comunidad, de conocimiento

y cultura, dinamizados, a su vez por las múltiples relaciones que se producen en la actual sociedad de la información.

\section{Synthesis}

In this article, it is proposed an analysis of the university educators roll and the communication in use in those social spaces. From a wide range of learning views, the author generates reflections about educomunication, community building, knowledge and culture, invigorated, in turn by the multiple relations that take place in the present-day information society

\author{
Danjel Prieto Castillo \\ d_prietoc@yahoo.com \\ Doctorado honoris causa en Comunicación Social, Universidad Pontificia \\ Bolivariana de Medellín
}

\begin{abstract}
"Generar un espacio de reflexión sobre el papel de los medios de comunicación y las nuevas tecnologías en la educación y en los procesos comunitarios para posesionar los derechos ciudadanos y públicos de la comunicación en la sociedad de la información y así fortalecer el movimiento de medios locales, públicos y educativos como expresión de participación ciudadana en la construcción del tejido social"
\end{abstract}

He reproducido el objetivo general de este encuentro como introducción a mi conferencia, porque su sentido se extiende a todo el tejido de la sociedad, en el cual están presentes las instituciones. Mi análisis se centrará en la comunicación vigente en espacios universitarios, que hemos podido reconocer a través de un proceso educativo de diez

\footnotetext{
* Encuentro internacional ondas y antenas participativas, Bogotá, 30 de agosto de 2005
} 
años, y de investigaciones sobre la situación de educadoras y educadores en tales espacios. El argumento central: el uso creativo de los medios de comunicación y las nuevas tecnologías en el campo de la educación, el ejercicio de los derechos ciudadanos y públicos en el seno de esas casas de estudios, se ve restringido por la carencia de una tradición de interaprendizaje y la escasa existencia de comunidades de aprendizaje. $Y$ tanto interaprendizaje como comunidades de aprendizaje son la condición de posibilidad de la educomunicación.

El punto de partida de estas reflexiones es una comprobación casi elemental:

La condición humana, la posibilidad de humanización de cada una y cada uno de nosotros está signada por el aprendizaje.

Y desde un comienzo, en el aprendizaje hay siempre otro:

Ganamos en humanización, nos volvemos seres humanos, a través de otros seres humanos.

Podemos decirlo de esta manera:

En el camino de alguien a sí mismo, siempre hay otro. Ese sí mismo significa el desarrollo de lo que se posee como potencialidades, de lo que se puede llegar a ser en la existencia.

Lev Vigotski había visto esto con una claridad estremecedora' ${ }^{1}$ cuando explicaba cómo se constituye la interioridad de un niño a través del habla que le presta su madre. Proceso de interiorización que permite luego la propia interioridad.

No hay habla posible sin el habla del otro.

Aprender del otro, entonces. Aprender con el otro. $Y$, elemento sustantivo en esa relación: la comunicación.

${ }^{1}$ VIGOTSKI, Lev S. La genialidad y otros textos inéditos, Edición al cuidado de Guillermo Blanck. Bs. As.: Almagestro,1998. 


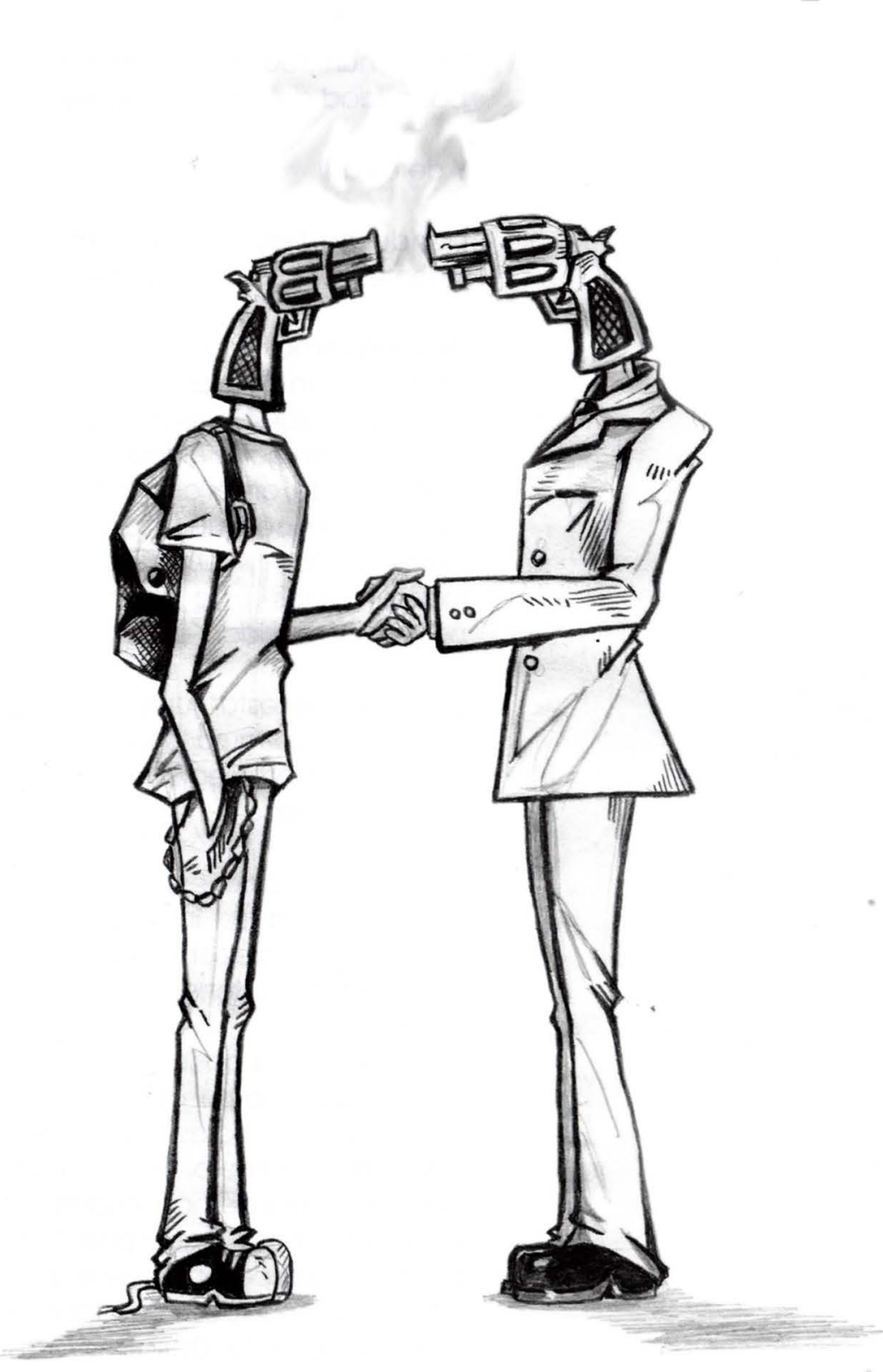

Educación y comunicación están a la base de nuestra humanización.

Es ése el alcance del término educomunicación.

Aprendemos del otro y con el otro. LO hacemos, entonces, en común unión, en com-unión. Desde allí todas las variantes: aprendizaje colaborativo, aprendizaje cooperativo, apoyo mutuo para aprender.

Hemos adherido, desde hace años, a las palabras de don Simón Rodríguez:

Todo aprendizaje es un interaprendizaje.

Para comprender el sentido de tan bella expresión, hace falta situarla en el marco de la filosofía básica del maestro:

Estamos en el mundo para entreayudarnos y no para entredestruirnos.

El interaprendizaje es el maravilloso recurso que tenemos para entreayudarnos en esta deriva de la existencia, como suele decir sabiamente Humberto Maturana ${ }^{2}$.

¿Qué sentido tiene aprender si no es para apoyarnos unos a otros, para sostenernos en el océano de la existencia?

Interaprendizaje en comunión supone comunidad. Lo digo de esta manera:

${ }^{2}$ MATURANA, Humberto, La realidad: ¿objetiva o construida?, Barcelona, Anthropos, 1996. 


\section{MMedianciones}

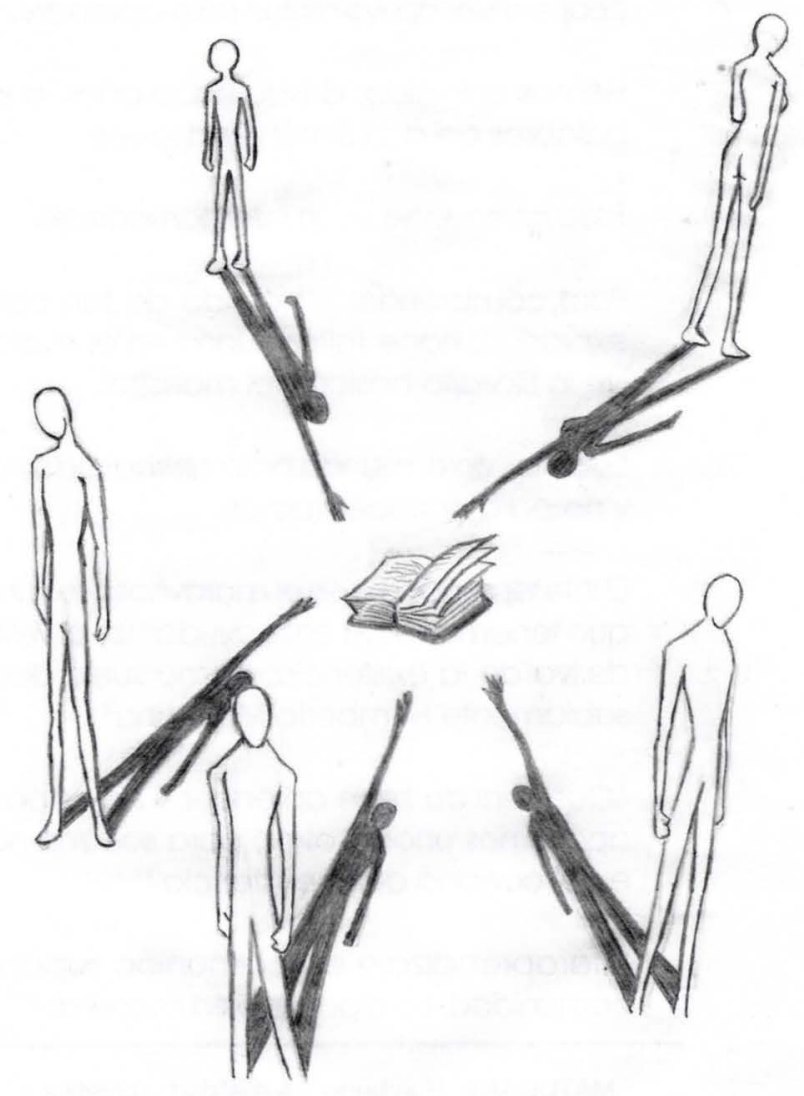

La comunidad es la condición de posibilidad del interaprendizaje.

Y de ésta:

Donde no hay comunidad, difícilmente hay interaprendizaje.

Despeguemos el concepto de su común connotación de comunidad popular. No rechazamos esa connotación generalizada, pero nos corresponde ampliarlo a todo tipo de posible comunidad: familias, organizaciones, instituciones educativas, radio emisoras... He afir-mado: "De posible comunidad".

El hecho de estar juntos en algún espacio no asegura la existencia de comunidad, no asegura, por lo tanto, el interaprendizaje.

Si la comunidad es la condición de posibilidad del interaprendizaje, necesitamos crecer en comunidades, crecer y sostenernos en ellas.

Supongamos la posible comunidad de un aula en la cual se comparten cuatro a cinco horas diarias. Treinta seres, por ejemplo. icuánto para aprender de los demás! icuánto para interactuar, para regocijarse con la palabra y la experiencia de todos! ¿y si no hay comunidad? ¿y si todo está organizado para desaprovechar 
esas preciosas existencias y concentrarse sólo en la voz de una de ellas, que habla desde una suerte de púlpito?

La comunidad siempre inquietó al poder.

Lo supo muy bien en su momento Piotr Kropotkin, quien en su libro El apoyo mutuo mostró el trabajo incesante de los poderosos en los siglos XVIII y XIX para destruir comunidades sociales ${ }^{3}$.

Encadenemos nuestras afirmaciones:

Puesto que la educomunicación se fundamenta en la maravillosa posibilidad humana del inter-aprendizaje, puesto que para el logro de este último la condición es la existencia de una comunidad, puesto que al poder autoritario le inquieta lo comunitario, la educomunicación, en la inflexión que ha venido teniendo en nues-tra América Latina, aparece en las antípodas de ese tipo de ejercicio del poder.

Y no me refiero sólo al poder político, al de dueños de haciendas y de vidas, al de los salvajes que vienen depredando espacios naturales y sociedades enteras, al de los halcones del Norte cuyas garras se hunden en todos los sures.

Me refiero también al otro, al poder más cercano, al que se entreteje en las instituciones y en las relaciones

\footnotetext{
3"El gobierno francés encontró que las asambleas populares comunales eran demasiado ruidosas, es decir, demasiado desobedientes, y en el año 1787 fueron sustituidas por consejos electivos compuestos por un alcalde y de tres a seis síndicos, que eran elegidos entre los campesinos más acomodados." Kropotkin Piotr, El apoyo mutuo, edición completa en la red, tp://www.kehuelga. org/biblioteca/apoyo/apoyo.html
}

más cotidianas. Me refiero, por ejemplo, al poder en el seno de las universidades, empecinado, en muchísimos establecimientos, en destruir comunidad.

\section{Interaprendizaje y educación formal}

El eje de análisis de las siguientes consideraciones pasa por la pregunta:

¿Existen comunidades en la educación formal dirigidas a permitir, a impulsar el interaprendizaje?

Nuestra respuesta, a partir de experiencias vividas en espacios universitarios argentinos, no es nada alentadora. En todo caso podemos matizar tal mirada mediante referencias a excepciones, pero aparecen como constantes el aislamiento, la soledad de educadoras y educadores.

Llevamos varios años, con un grupo de colegas, recogiendo testimonios sobre esa ausencia de comunidad. Desde 1995 dirijo en la Universidad Nacional de Cuyo, Mendoza, Argentina, una Carrera de Posgrado de Especialización en Docencia Universitaria. Han égresado, mediante modalidad a distancia, más de 1200 colegas de todas las disciplinas y de distintas casas de estudio. La base de la Especialización es la práctica de los docentes, trabajamos sobre ella proponiendo conceptos, metodologías y líneas de acción, pero apoyados siempre en la vida, la experiencia y la memoria de cada participante. La condición de aprobación de cada uno de los cuatro módulos es la elaboración de un texto paralelo, recurso que caracterizamos con Francisco Gutiérrez como "el seguimiento y el registro del aprendizaje a cargo del propio aprendiz". Pues bien, desde 1995 a la fecha hemos atesorado más de 5000 textos paralelos producidos por médicos, sociólogos, 
ingenieros, comunicadores, abogados, arquitectos...; varones y mujeres, con una fuerte mayoría de estas últimas. En esos materiales hay testimonios que muestran percepciones, vivencias, frustraciones, alegrías de nuestras educadoras y nuestros educadores.

Hemos realizado investigaciones sobre el proceso vivido ${ }^{4}$ y hemos reflexionado de manera constante en torno a lo expresado por tantos colegas. Desde ese suelo nutricio de experiencias he podido reconocer, dolorosamente, lo que llamo las acechanzas al interaprendizaje.

Me detengo en el concepto: Engaño o artificio para hacer daño a alguien.

Seguimiento de una presa, sin que ella lo note.

4"El modelo de la mediación pedagógica en la capacitación docente universitaria. Una reflexión sobre la práctica desde los actores involucrados", que dirigió Estela Brandi con la participación de tres de nuestras asesoras pedagógicas: Elsa Cabrini, María Teresa Guajardo y Marta Pisi y mi colaboración como director del posgrado; Mendoza, 1999-2001.

"Mediación pedagógica con toda la

cultura", análisis de textos paralelos, bajo mi dirección, Mendoza 2003.

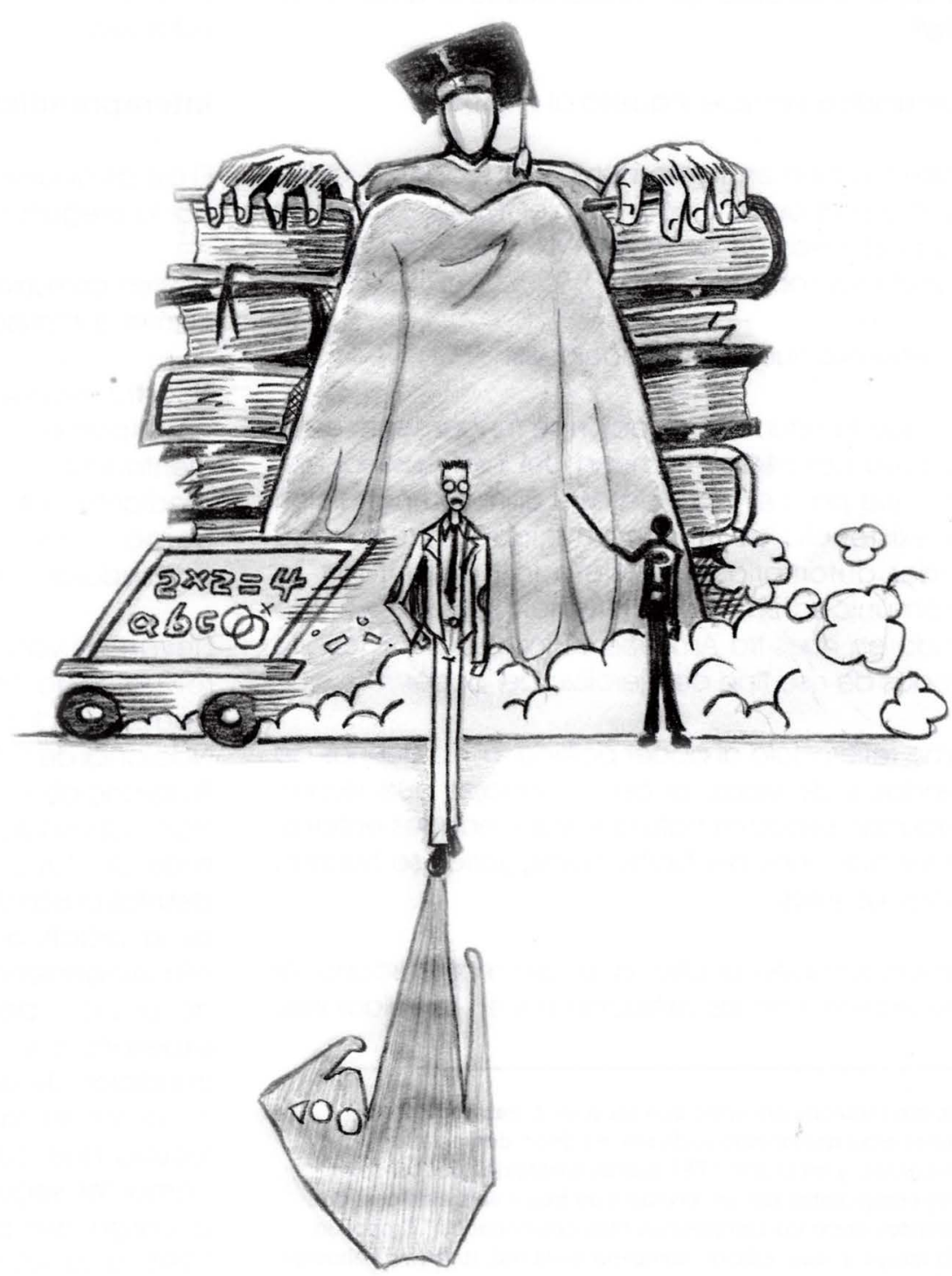


Y añado:

La asechanza desde el contexto: el que asecha en el umbral de tu existencia, de tu ser.

La acechanza desde uno mismo: el que acecha tras el umbral, el tuyo, el de cada quien, a fuerza de vivir acechado acabas por acecharte.

Lo siniestro: alguien acechado desde sí mismo y desde el contexto: el horror de no saber desde dónde te acechan.

Estoy diciendo, queridas, queridos amigos, que en nuestra experiencia de diez años de reunión de testimonios de colegas universitarios, hemos recogido sobradas muestras de lo que significa vivir acechado en el seno de nuestras instituciones, lo cual tiene un terrible efecto en la posibilidad de creación de comunidad y de la práctica del interaprendizaje.

\section{Las asechanzas al interaprendizaje}

Comienzo por la más común y quizá más terrible:

-La asechanza de la soledad.

Siempre me ha afectado, enternecido, dolido, la soledad del educador. Estás muy solo cuando te toca correr de un lado a otro de la ciudad para completar 40 o 50 horas de trabajo, durante las cuales desfilan rostros, miradas, risas, como en un vértigo de espejos multiplicados, que dejan apenas imágenes fugaces y superficies frías.

La soledad puede minar cualquier ánimo, cualquier temple, cualquier entusiasmo. La entropía acecha a los solitarios, a estos solitarios condenados a serlo ante y entre los otros.

Entre los condenados a la soledad, el interaprendizaje se reduce al mínimo, al cruce de superficies de seres que apenas si interactúan en medio del tráfago de la supervivencia cotidiana.

\section{La segunda asechanza:}

-El poder entronizado en la institución.

Uso el término entronizar en todos sus sentidos:

Alguien colocado en un trono, ensalzar a uno, engreírse.

El viejo discurso universitario campea todavía en nuestros establecimientos sin mayores frenos. Podemos reconocerlo en la fragmentación de conocimientos, en la estructura perversa de la cátedra tradicional ${ }^{5}$ que permite una concentración en el titular de la sabiduría general del grupo y de las decisiones fundamentales sobre contenidos y metodologías; en la división entre ciencias legitimadas y otras condenadas al papel de siervas; en los juegos de alianzas capaces de sostener casi a perpetuidad a pequeños grupos en los cargos importantes... La universidad, avanzada de la conciencia y la cultura en la sociedad, espacio de defensa de la democracia, suele estar plagada de autoritarismo. También aquí, el poder es enemigo de la comunidad de educadoras y educadores, enemigo de las comunidades de aprendizaje ${ }^{6}$.

${ }^{5}$ La cátedra nació hace siglos sostenida por la creencia de que junto a un gran maestro crecen los discípulos. ¿Qué sucede cuando al frente de ella no hay un gran maestro?

${ }^{6}$ Asumo lo extremo de estas afirmaciones, pero no me desdigo de ellas. Bellas son las excepciones y bienvenidas las que vendrán. 


\section{Tercera asechanza:}

-La desaforada competencia por migajas de figuración social y migajas de salarios.

La década del 90 trajo a nuestro contexto la demanda de evaluación institucional y de educadores. No rechazamos esa demanda, nada más soberbio que una organización empecinada en creer que nadie puede evaluarla. Pero, al menos en mi país, se ha desatado desde mediados de esa década una carrera por acumular antecedentes, por juntar papeles $y$ papelitos, por engordar como sea la hoja de vida, con el consiguiente miedo, terror al otro, al que ha juntado más y puede dejarte fuera con un golpe de curriculum vitae. No pretendo describir una guerra de todos contra todos, pero tampoco puedo dejar de referirme a una constante tensión por ser alguien dentro de las reglas de juego impuestas a menudo por burócratas. Y en esa contienda cotidiana, crece la desconfianza en todas direcciones. Lo cual nos lleva a una comprobación dolorosa:

Es muy difícil aprender de alguien en quien no se confía, en quien no se cree.

¿Cómo impulsar así comunidad? ¿Cómo sostener el interaprendizaje?

\section{Cuarta asechanza:}

-El adelgazamiento del tiempo humano, o la exacerbación del fast time.

Llamo humano al tiempo del compartir, de la convivencia, del goce de la reflexión, de la contemplación, de la mirada serena, de la escucha. Llamo fast time a esas miserias de tiempo que nos dejan una sociedad y unas instituciones empecinadas en igualarlo todo a la miseiia del fast food, del fast love, del fast life. Una de las constantes de los testimonios de nuestros colegas es el dolor de no tener tiempo para la lectura, para la meditación, para la escritura, para la interacción.

Cuando a alguien le niegan su tiempo, le niegan posibilidades de su ser, le niegan su ser.

¿Cómo sostener comunidad en medio de la fatiga diaria, de la incertidumbre constante, del salto continuo de un escenario y de un conjunto de seres a otros? ¿Qué lugar hay para el interaprendizaje en ese vértigo, en esa deriva frenética?

\section{Quinta asechanza:}

-El debilitamiento de la voluntad de aprender y de interaprender.

Abramos las miradas más allá de las aulas universitarias: si alguien planificara una manera de sostenerse en el poder quebrando moral y económicamente determinado país, un camino para hacerlo sería sin duda el debilitamiento de esa voluntad en las nuevas generaciones. No digo esto por noticias, lo he vivido en mi patria. El quiebre de la voluntad de aprender se impulsa por exclusión y abandono de grandes mayorías de la población, por dádivas envilecedoras, por generalización de una cultura del oportunismo y de la picaresca, por entronización de la ley del menor esfuerzo, del sálvese quien pueda a costa de quien sea. El Movimiento de los Sin Techo, que desarrolla su acción en la ciudad de Santa Fe desde hace más de 15 años, ha comprobado en su trabajo cotidiano el creciente debilitamiento de la voluntad de aprender de sectores marginales y excluidos de la sociedad. Por supuesto, 
como veremos más adelante, siempre hay caminos de resistencia, pero las tendencias están presentes.

Volvamos a los espacios que nos ocupan: ¿qué sucede cuando a quien se le debilita, se le quiebra la voluntad de aprender es una educadora o un educador? Lo escuché una vez de labios de un colega, por estas tierras nuestras de Dios y del diablo:

"Voy a clase a ver qué hago, yo ya no tengo nada que decir."

Nada que decir, nada que aprender, náda que interaprender. Tragedia del educador y tragedia para sus estudiantes ${ }^{7}$.

\section{Sexta asechanza:}

\section{-La entropía comunicacional.}

En el 2000 tuve el honor de coordinar un diagnóstico de comunicación de la Universidad José Simeón Cañas, la UCA de El Salvador. Trabajamos en aquella oportunidad en varias mesas de diálogo y reflexión:

- La comunicación en la educación.

- Comunicación y medios.

- Comunicación y centros de información y documentación.

- Tecnologías de la información y la comunicación.

- Comunicación y gestión.

- Comunicación y matriz académica.

- Comunicación y proyección social.

${ }^{7}$ No podemos dejar de mencionar aquellos casos en que el docente o la docente consideran que todo lo han aprendido, que nada queda por delante para ampliar el saber. Igual tragedia, sin duda.
Si traigo esta información aquí es porque en cada uno de esos temas está presente una posible línea de reflexión y acción de la educomunicación. Y también en cada uno se plantea la posibilidad de la entropía comunicacional.

La experiencia de estos diez años el Posgrado en Docencia Universitaria nos ha permitido reconocer no sólo la presencia de esa entropía, sino también el apoyo a lá misma. Una entropía comunicacional generalizada suele ser aliada del poder; a menor comunicación, a menor relación con la sociedad, a menores impulsos al interaprendizaje, más alternativas de sostener un estado de cosas favorable a grupos hegemónicos dentro de nuestras instituciones. Lo comunicacional, y mucho más lo educomunicacional, no suele ser objeto de análisis, mucho menos de diagnóstico ${ }^{8}$ en nuestros espacios universitarios. Para decirlo sin sutilezas:

La entropía comunicacional es un buen negocio para quienes sostienen viejas formas de relacionarse y de dominio en el ámbito de los estudios superiores.

Reúno las seis acechanzas:

-La soledad de educadores y educadoras;

-El poder entronizado en la institución; - La desaforada competencia por migajas de figuración social y migajas de salarios;

-El adelgazamiento del tiempo humano, o la exacerbación del fast time;

\footnotetext{
${ }^{8}$ Llevo décadas insistiendo en la necesidad del diagnóstico comunicacional de las instituciones universitarias sin encontrar casi ningún eco; el caso de la UCA de El Salvador es excepcional, porque se trata de una institución fuerte, bien parada y profundamente comunicada con su contexto
} 
-El debilitamiento de la voluntad de aprender y de interaprender;

-La entropía comunicacional.

¿Agoto con ellas todas las posibles acechanzas? De ninguna manera, sólo presento algunas que han aparecido con más fuerza en los materiales producidos por nuestros colegas.

\section{Consecuencias de las asechanzas}

Saquemos algunas consecuencias de lo presentado hasta ahora:

a. El ideal del interaprendizaje como fundamento de la educomunicación navega a contraviento de tendencias sociales e institucionales en buena parte de nuestros países. No reconocemos fácilmente movimientos generalizados a favor de la ruptura de la soledad, de la distribución del poder, de la reducción de la competencia... Por el contrario, la década del noventa y lo que va de ésta tienden a acentuar esas tendencias.

b. Los procesos a los cuales hacemos referencia son acumulativos, tanto en lo institucional como en lo personal. Una universidad que por décadas cultiva sistemáticamente la entropía comunicacional, difícilmente saldrá de ella en unos pocos meses. Pesa en todo esto el tiempo largo de las instituciones. Un ser humano golpeado por esas acechanzas, necesita mucha capacidad de resistencia para salir sin heridas de tanta agresión. Y las heridas no desaparecen como por magia, dejan huellas en la piel y en el corazón.

c. La comunicación no brota límpida, como de fuentes incontaminadas, en cualquier situación social. La comunicación es una trama muy sensible a todos los vientos de la relación humana. Las acechanzas mencionadas inciden sin tregua en esa delicada trama, para colmarla de vacilaciones, de silencios, de dudas, de suspicacias. Frágil cristal, la comunicación se quiebra a menudo para siempre.

d. Los llamados a la interdisciplina en muchas de nuestras instituciones carecen de sentido si se los lanza en medio de todas las acechanzas señaladas. No estamos ante una indiferencia interdisciplinaria, sino ante una carencia de lazos entre los seres humanos. La condición de posibilidad de la interdisciplina pasa por el desmonte de las acechanzas.

e. No es correcto, al menos para muchas instituciones, hablar de "comunidad universitaria". El pasar juntos ciertos tiempos en un determinado campus o edificio, no asegura para nada la construcción de una comunidad. Estamos ante casas de estudios fragmentadas en facultades, carreras, disciplinas, cátedras y asignaturas. Y sin comunidad no hay interaprendizaje.

f. Una estructura semejante no favorece el impulso al conocimiento ni a la creación de cultura; no puede aspirar demasiado a sembrar la comunicación y el interaprendizaje entre los estudiantes; no reúne las condiciones para que cada educador o educadora logre lo mejor de sí como profesional y como persona. La reducción al mínimo de comunidad y de alternativas para el aprendizaje deja huellas persistentes en los trabajadores de la educación. Cada quien sabe hasta dónde pudo haber llegado y no llegó. 
g. Es terrible para una institución educativa que sus docentes pierdan parte o toda su voluntad de aprender. Más terrible aún es que esto termine por contaminar a las estudiantes y los estudiantes.

Veamos las consecuencias de todo lo expresado para el interaprendizaje, entendido como elemento clave de la educomunicación:

- Es muy difícil aprender de alguien con quien poco me comunico, mal me comunico o no me comunico;

- Es muy difícil aprender de alguien con quien no comparto tiempos, porque ni él ni yo los tenemos;

- Es muy difícil aprender de alguien en quien no creo;

- Es muy difícil abrirme a otras disciplinas si apenas puedo, por condicionamientos de soledad y de aislamiento, sostener la mía;

- Es muy difícil aprender de alguien en medio de tendencias entrópicas generalizadas en $\mathrm{mi}$ institución;

- Es muy difícil aprender de otro si ha sido minada mi voluntad de aprender;

- Es muy difícil enseñar, promover y acompañar el aprendizaje de las jóvenes y los jóvenes estudiantes si ha sido minada mi voluntad de aprender.

¿Guerra de todos contra todos, entonces? ¿Desolación, aislamiento, violencia constantes que caracterizan a nuestras universidades? ¿Dominación sin márgenes, sometimientos sin remedio? ¿Frustraciones, postergaciones del propio ser, de sueños e ideales?

No tengo ninguna intención de pintar un cuadro de horrores y miserias humanas. La universidad argentina ha sido sostenida por sus educadores con salarios congelados desde 1992, en medio de un deterioro vertiginoso de la sociedad en su conjunto. Habitan nuestros espacios seres maravillosos, capaces de impulsar en medio de todos los condicionamientos una labor educativa. Pero las acechanzas han existido y existen. Si hablamos desde la educomunicación, desde la pregunta por el interaprendizaje, no podemos taparnos los ojos ante realidades demasiado prolongadas en el tiempo. ¿Problema estructural? Sin duda, pero sostenido por algunos seres humanos que defienden a menudo migajas de privilegios.

No olvidemos la existencia de intentos de transformación pedagógica mediante la incorporación de recursos tecnológicos. Nuestras casas de estudios no han estado al margen de esas innovaciones y podemos mencionar casos muy valiosos, entre otros, el impulso a círculos de estudios a través de las tecnologías digitales. Pero también corresponde reconocer que esas innovaciones a menudo son colonizadas por la estructura institucional dominante, con lo que sus posibilidades se estrechan y acaban perdiendo sus potencialidades para la educación.

\section{Las ásechanzas en la trama de la sociedad}

¿Es posible llevar estas reflexiones a otros tipos de instituciones? Estoy convencido de ello. En cualquier espacio social existen posibilidades y acechanzas al interaprendizaje. Comencemos por la familia. Venimos viviendo en los últimos años un creciente, y terrible, adelgazamiento de la cultura familiar, entendida ésta como todo lo que permite sostener a quienes integran ese grupo en la vida: tiempo para compartir y convivir, para gozar la presencia de los demás, para jugar, para la escucha, para el interaprendizaje. Tal adelgazamiento proviene de la agresión desde los poderes de la sociedad. Pero no podemos dejar de recordar que 
también en las familias se pueden vivir el autoritarismo y la violencia, ambos contrarios a la construcción de comunidad.

¿Quedan al margen de las acechanzas las organizaciones empecinadas en ampliar desde la base de la sociedad la democracia en nuestros países? Deberían quedar, pero las presiones del contexto son terribles e inciden en algunos de los puntos indicados, como el tiempo por ejemplo. Y no podemos idealizar ninguna organización, porque también en ellas pueden darse juegos de poder de base autoritaria.

Podríamos ampliar: el Estado, las empresas privadas, los organismos de salud, los otros niveles del sistema educativo. No existe espacio social alguno libre de acechanzas.

Pero a la vez, y con toda fuerza, no creemos que haya espacio social alguno vacío de búsquedas en el terreno del aprendizaje y del interaprendizaje. En la experiencia narrada en los textos paralelos escritos por nuestros colegas, difícilmente encontramos a alguien quebrado de por vida por las asechanzas. Por el contrario, afloran casi en todos los casos búsquedas y resistencias; estrategias para enfrentar el autoritarismo, impulsos al interaprendizaje entre las estudiantes y los estudiantes cuando la institución cerraba caminos a hacerlo con los colegas. Aprendimos de esos testimonios que nunca las tendencias hegemónicas ocupan todo el escenario, nunca terminan por quebrarle la espalda y la mirada a las educadoras y los educadores; por todas partes, en nuestro universo de más de 1200 egresados, brotan intentos de remontar la entropía, de desandar las estrechas sendas fijadas por las asechanzas para abrir anchos caminos hacia la relación de interaprendizaje con los otros.

\section{La resistencia}

Lo vivido en nuestro posgrado, lo recogido de las vivencias de nuestros colegas, no ha hecho más que confirmar la dialéctica de la vida en todas nuestras sociedades:

-Ningún sistema autoritario agota las resistencias con sus asechanzas.

Ninguno. Ni las burocracias educativas, ni los halcones del Norte, ni los avasallamientos económicos y sociales, ni las agresiones a nuestros niños y jóvenes, ni las incitaciones a reducir la maravillosa complejidad de cada ser humano a la competencia y el consumo.

Contra viento y marea, los ideales del interaprendizaje, de la escuela de educomunicación latinoamericana siguen tan vigentes como hace 50 años. Y seguirán, porque están anclados hasta el corazón en los alcances de la maravillosa expresión de don Simón Rodríguez:

"Estamos en el mundo para entreayudarnos y no para entredestruirnos". 


\section{Bibliografía}

CABRINI Elsa, GUAJARDO María Teresa, PISI Marta, BRANDI Estela, "El modelo de la mediación pedagógica en la capacitación docente universitaria. Una reflexión sobre la práctica desde los actores involucrados", que dirigió con la participación de tres de nuestras asesoras pedagógicas, Mendoza, 1999-2001.

KROPOTKIN, Piotr، El apoyo mutuo, edición completa en la red, $\mathrm{tp}$ ://www.kehuelga.org/biblioteca/apoyo/apoyo.html.

MATURANA, Humberto, La realidad: ¿objetiva 0 construida?, Barcelona, Anthropos, 1996.

PRIETO CASTILLO, Daniel,"Mediación pedagógica con toda la cultura", análisis de textos paralelos, Mendoza 2003.

VIGOTSKI, Lev S. La genialidad y otros textos inéditos, Edición al cuidado de Guillermo Blanck. Bs. As.: Almagestro, 1998. 